\title{
17ß-Estradiol Stimulates Generation of Reactive Species Oxygen and Nitric Oxide in Ovarian Adenocarcinoma Cells (OVCAR 3)
}

\author{
Jafar Maleki ${ }^{1}$; Mitra Nourbakhsh ${ }^{1,2}$; Mohammad Shabani ${ }^{1, *}$; Mohsen Korani ${ }^{3}$; Seyed \\ Manuchehr Nourazarian ${ }^{4}$; Mohammad Reza Ostadali Dahaghi ${ }^{5}$; Mohamad Hossein \\ Moghadasi ${ }^{6}$
}

${ }_{1}^{1}$ Department of Biochemistry, Iran University of Medical Sciences, Tehran, IR Iran

${ }_{3}^{2}$ Metabolic Disorders Research Center, Endocrinology and Metabolism Research Institute, Tehran University of Medical Sciences, Tehran, IR Iran

${ }^{3}$ Department of Biochemistry, Baqiyatallah University of Medical Sciences, Tehran, IR Iran

${ }_{5}^{4}$ Department of Laboratory Sciences, Tabriz University of Medical Sciences, Tabriz, IR Iran

${ }_{6}^{5}$ Hematology-Oncology and Stem Cell Transplantation Research Center, Shariati Hospital, Tehran University of Medical Sciences, Tehran, IR Iran

6 Departement of Laboratory, Labafi Nedjad Hospital, Social Security Organization, Tehran, IR Iran

${ }^{*}$ Corresponding author: Mohammad Shabani, Department of Biochemistry, Iran University of Medical Sciences, Tehran, IR Iran. Tel: +98-2188622742, E-mail: shabani.mo@iums.ac.ir

Received: January 3, 2015; Revised: January 19, 2015; Accepted: February 3, 2015

\begin{abstract}
Background: Experimental and epidemiological evidence supports a role for steroid hormones in the pathogenesis of ovarian cancer. Among steroid hormones, 17ß-estradiol (E2) has the most potent effect on proliferation, apoptosis and metastasis.

Objectives: In the present study, we investigated the effect of E2 on production of ROS and NO in ovarian cancer cells.

Materials and Methods: Ovarian adenocarcinoma cell line (OVCAR-3) was cultured and treated with various concentrations of E2, antioxidants (N-acetyle cysteine and Ebselen) and ICI182780 as an estrogen receptor antagonist. MTT test was performed to evaluate cell viability. NO and ROS levels were measured by Griess and DCFH-DA methods, respectively.

Results: ROS levels as well as NO levels were increased in OVCAR-3 cells treated with E2. The increase in ROS production was in parallel with increased cell viability which indicates that estrogen-induced ROS can participate in cancer progression. ICI182780 abolished E2-induced ROS production. Progesterone was also effective in reducing ROS and NO generation.

Conclusions: NO and ROS are important molecules in signaling networks in cell. These molecules can be used as therapeutic targets for prevention and treatment of ovary cancer and other estrogen-induced malignancies.
\end{abstract}

Keywords: Reactive Oxygen Species; 17ß-estradiol; Ovarian Adenocarcinoma Cells; DCFH-DA

\section{Background}

Ovarian cancer is the fourth most frequent cause of cancer death and the most lethal of all gynecologic tumors in women (1). Estrogens are implicated in tumor progression by increasing cell proliferation as well as promoting invasion or cell mobility. Although circulating levels of estrogens are usually low, in situ aromatase conversion of androgens can locally produce high estrogen levels in ovarian tumors (2). There are 9 different estrogens in human blood circulation that three of them are major, including: 17 $\beta$-Estradiol (E2), Estrone (E1), and Estriol (E3). E2 is the predominantly circulating estrogens and the most biologically active ovarian steroid (3). E2 is the most potent estrogen regarding the influence on proliferation, apoptosis and metastasis (4). Ovarian cancer cells also express $17 \beta$-hydroxysteroid dehydrogenase (17 $\beta$-HSD) and are able to convert androstenedione (a weak androgen) to testosterone (5, 6 ). The classic genomic model of estrogens function is initiation genes transcription involved in cell growth by binding to estrogen receptors (ER). However, nongenomic functions for estrogens via intracellular signaling cascades have also been reported (7). Estrogen receptors are also found in mitochondria and estrogens have substantial effects on mitochondrial biogenesis and metabolism, therefore may induce ROS generation in this way $(3,8)$. In addition, oxidant-induced damage

Copyright (C) 2015, Iranian Journal of Cancer Prevention. This is an open-access article distributed under the terms of the Creative Commons Attribution-Non Commercial 4.0 International License (http://creativecommons.org/licenses/by-nc/4.0/) which permits copy and redistribute the material just in noncommercial usages, provided the original work is properly cited. 
to DNA, 17ß-estradiol-generated ROS can induce lipid peroxidation and oxygen radical-mediated oxidation of amino acid residues of proteins to carbonyl-containing moieties (9). Initiation and/or functioning of several signal transduction pathways rely on the action of ROS as signaling molecules which may act on different levels in the signal transduction cascade (10). Signaling proteins, including protein tyrosine phosphatases and several transcription factors, that contain critical cysteines are sensitive to redox changes and thus are potential targets for modifications by ROS. ROS-mediated signaling pathways have been shown that contribute to initiation, promotion and progression of cancer (11). Nuclear factor-кB (NF- кB) a major redox-sensitive transcription factor that responsible for the induction of pro-inflammatory genes and represents a hallmark of inflammation-associated carcinogenesis. Activation of NF- $\mathrm{\kappa B}$ by ROS has been observed during neoplastic transformation (12). In addition, ROS and nitric oxide (NO) molecules are able to penetrate the plasma membrane and directly modulate the catalytic activity domain of transmembrane receptors of cytoplasmic signal transducing enzymes, thus leading to abnormal activation of transcription factors (13). The involvement of NO in the ovarian function modulation is documented by several studies (14).

\section{Objectives}

In the present study, we investigated the effect of E2 on production of ROS and NO in ovarian cancer cells.

\section{Materials and Methods}

Each experiment was carried out in triplicate to ensure consistency of the findings.

\subsection{Cell Culture and Treatment}

Ovarian adenocarcinoma cell line- 3 (OVCAR-3) were cultured in RPMI-1640 supplemented with 10\% fetal bovine serum (FBS), $10 \mu \mathrm{g} / \mathrm{mL}$ insulin and penicillin-streptomycin, at $37^{\circ} \mathrm{C}$ in a humidified incubator containing $5 \% \mathrm{CO}_{2}$. Before treatment, medium was removed and replaced with phenol red-free medium containing 5\% dextran-coated charcoal-stripped FBS for an additional 24 hours. Cells were treated with either various concentrations of E2 or vehicle alone. Cells were also cultured with estrogen together with antioxidants (N-acetyle cysteine (NAC) or Ebselen), progesterone, or ICI 182780 (estrogen receptor antagonist).

\subsection{MTT Assay}

Cells were grown in 96 well plates until 50\% confluent and treated by concentrations of $0.1-1000 \mathrm{nM}$ of E2 as described above. After 48 hours, supernatant was removed and $100 \mu \mathrm{L}$ of cell culture medium plus 10\% MTT dye $(\mathrm{W} / \mathrm{V})$ was added to each wells. The plates were incubated for 3 hours. The resulting formazan crystals were solubilized by DMSO. Optical density was determined by in $570 \mathrm{~nm}$. Each individual experiment was repeated at least 3 times.

\subsection{Measurement of Reactive Oxygen Species (ROS)}

Intracellular ROS levels were analyzed by flow cytometry using DCHF-DA, which is converted to DCHF by intracellular esterase enzymes. Oxidation of DCHF-DA in cells produces 2',7'-dichlorofluorescein (DCF) that has fluorescence characteristics. Fluorescence intensity is proportional to oxidants levels in cells. Cells were treated with tert-butyl hydroperoxide (ТBHP) as a positive control. In order to eliminate the effect of superoxide dismutase (SOD) on TBHP or nitrite peroxide production by nitric oxide synthase (NOS), diethyldithiocarbamate (DETCA) and NG-Monomethyl-L-arginine, monoacetate salt (L-NMMA) were used as SOD and NOS inhibitors, respectively.

OVCAR- 3 cells were seeded at a density of $3 \times 105$ cells well. Cells were then treated with various concentrations of hormones, antioxidants (Ebselen and NAC) or ICI182780 (Inhibitor of estrogen receptor). Untreated cells and treated cells were harvested in full serum media, spun down for 5 minutes at $1000 \mathrm{rpm}$ and resuspended in PBS containing $10 \mu \mathrm{M}$ DCHF-DA. Cells were maintained at $37^{\circ} \mathrm{C}$ in dark place for 30 minutes to 'load' the dye. Then cells were pelleted and resuspended in PBS and finally analyzed by flow cytometry, (Becton Dickinson model FACS Calibur).

\subsection{Measurement of Nitric Oxide Levels}

NO levels were determined by Griess method (15). NO levels were measured in cell culture supernatant after filtration to remove interfering proteins. Reduction of nitrate to nitrite was performed by nitrate reductase $(0.4 \mathrm{U} / \mathrm{mL})$ in the presence of $10 \mathrm{mM} \beta$-NADPH. Fifty microliters of supernatants were mixed with the same volume of Griess reagent ( $1 \%$ sulfanilamide, $0.1 \%$ naphthylethylenediamine chloride, $\left.2.5 \% \mathrm{H}_{3} \mathrm{PO}_{4}\right)$ and incubated at room temperature for 30 minutes. Optical density was measured in $540 \mathrm{~nm}$ by plate Reader (Dynex Technologies). A standard curves was produced to calculate NO concentrations.

\subsection{Statistical Analyses}

Data are expressed as mean \pm S.E. Statistical analyses 
were performed using analysis of variance (ANOVA) followed by Tukey's post hoc test (GraphPad Software Ver.5). $\mathrm{P}<0.05$ was considered as statistically significant.

\section{Results}

Human OVCAR-3 adenocarcinoma cells have been shown to express estrogen receptors. In this study, cell proliferation was significantly induced by E2 characterized by increased cell viability (Figure 1).

The optimal viability was achieved by E2 dose of $100 \mathrm{nM}$ $(\mathrm{p}<0.001)$.

The ability of various concentrations of E2 on rate of reactive oxygen species (ROS) generation was investigated in our study. An increase in intracellular peroxide levels was detected in E2-treated cells, and the $100 \mathrm{nM}$ dose of E2 induced the highest levels of ROS production (Figure 2).

E2-mediated ROS production was blocked by the addition of the antioxidants, N-acetyl-L-cysteine (NAC) and Ebselen (Figure 3). ICI182780 which is the ER antagonist could significantly abrogate ROS production by E2. Cotreatment of OVCAR-3 cells with $100 \mathrm{nM}$ E2 and progesterone also resulted in reduced ROS generation compared to E2 treatment $(\mathrm{P}<0.001)$ (Figure 3 ).

NO production was found to be increased in OVCAR-3 cells treated with E2, with $1000 \mathrm{nM}$ concentration being the most effective d ose of E2 $(\mathrm{P}<0.001)$. In cells treated with both E2 and progesterone, NO levels were not significantly different with control cells (Figure 4).

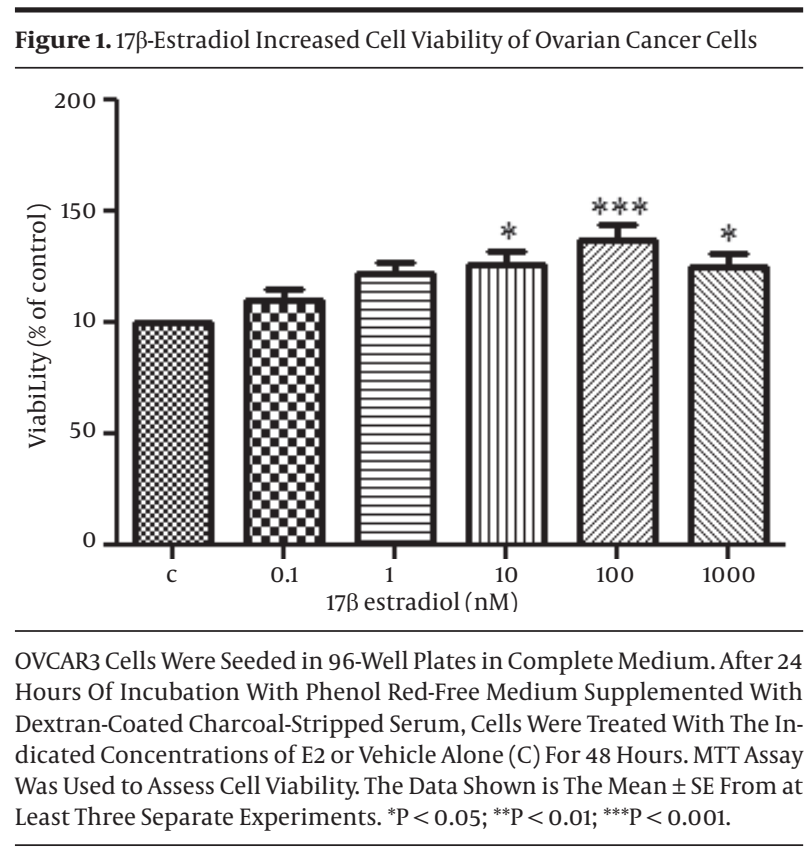

A

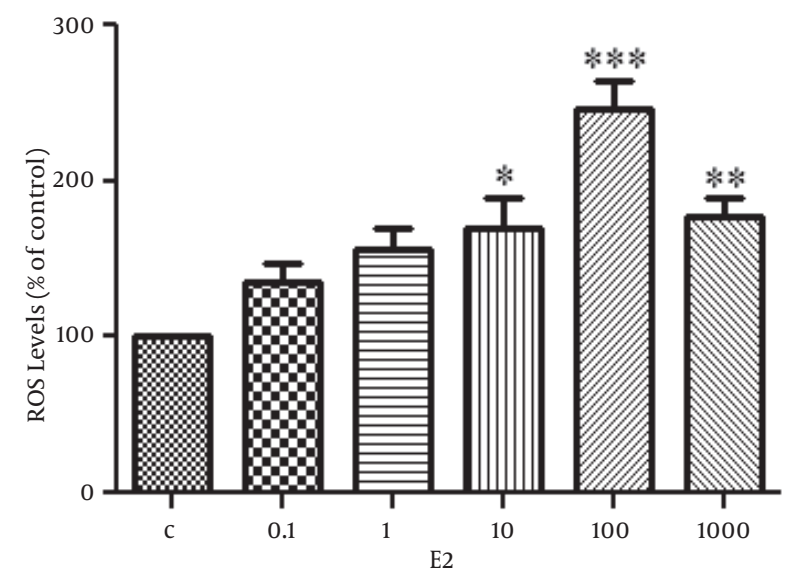

B
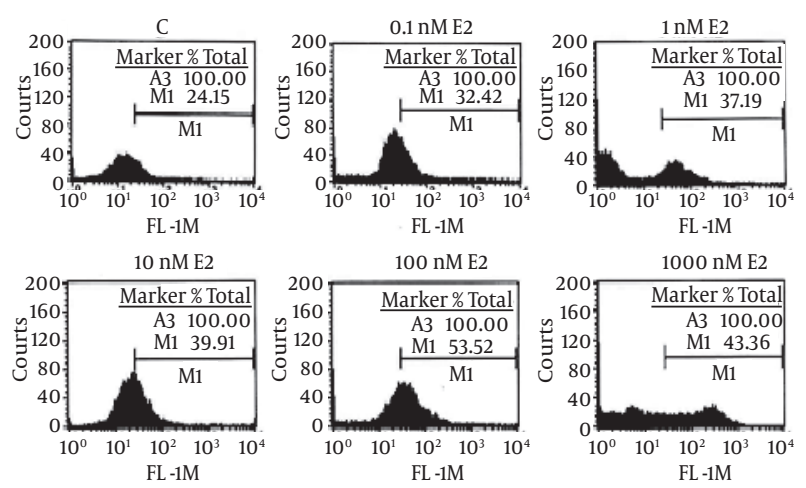

Cells Were Seeded at $3 \times 105$ Cells Per Well. After Serum Starvation for 24 hours Cells Were Treated With Various Concentrations of E2 for 24 hours. (B) Cells Were Pre-Treated With 1.0 Mm NAC, Ph 7.0 or $40 \mu \mathrm{m}$ Ebselen For 4 H Before DCF Assay. Cells Were Also Treated With E2 (100 Nm) Together With Progesterone (P4) (10 - 6 M). And ICI182780 (ICI) (10 - 5M). The Data Shown is the Mean \pm SE From at Least Three Separate Experiments. *P < 0.05; ${ }^{* *} \mathrm{P}<0.01$; ${ }^{* * *} \mathrm{P}<0.001$. 
Figure 3. (A) Cells Were Treated With 1.0 Mm NAC, Ph 7.0 or $40 \mu \mathrm{m}$ Ebselen for 4 hours Before DCF Assay

A

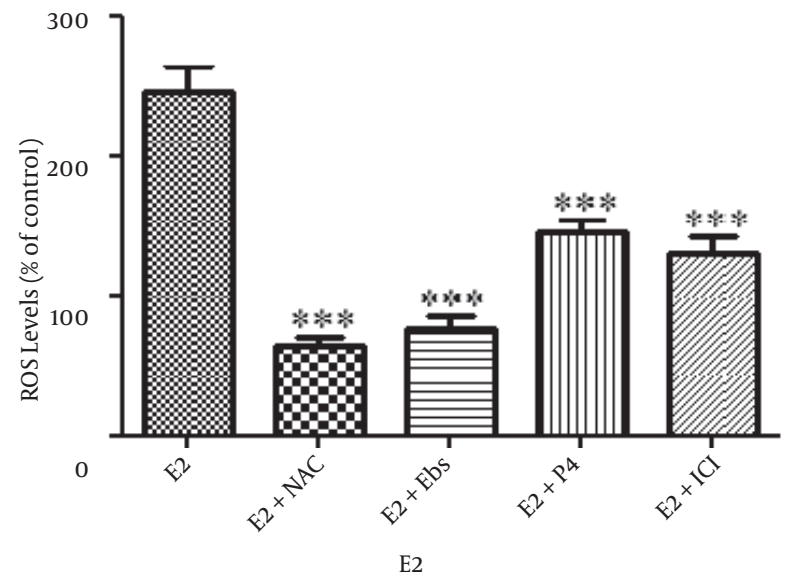

B
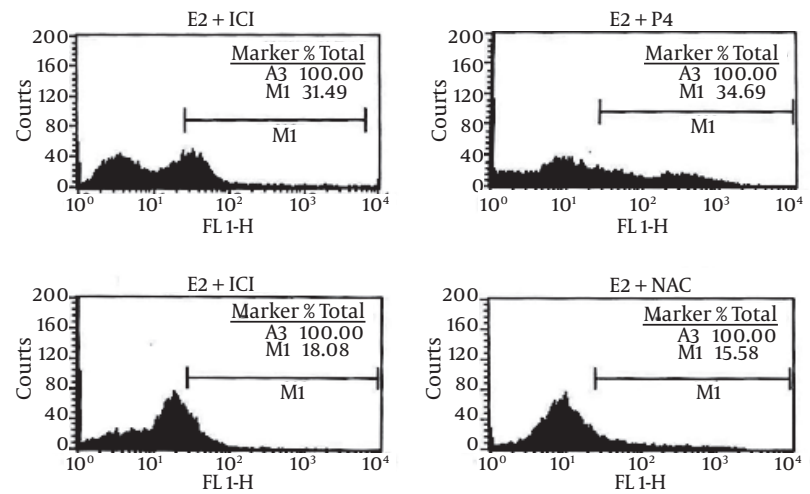

Cells Were Also Treated With E2 (100 Nm) Together With Progesterone (P4) 10 - 6M. And ICI182780 (ICI) 10 - 5M. (B) Results of ROS Levels as Determined by Flow Cytometry Using the Fluorescent Probe Dichlorofluorescein Diacetate (DCF-DA). The Data Shown is the Mean \pm SE From at Least Three Separate Experiments. ${ }^{*} \mathrm{P}<0.05 ;{ }^{* *} \mathrm{P}<0.01 ;{ }^{* * *} \mathrm{P}<0.001$.

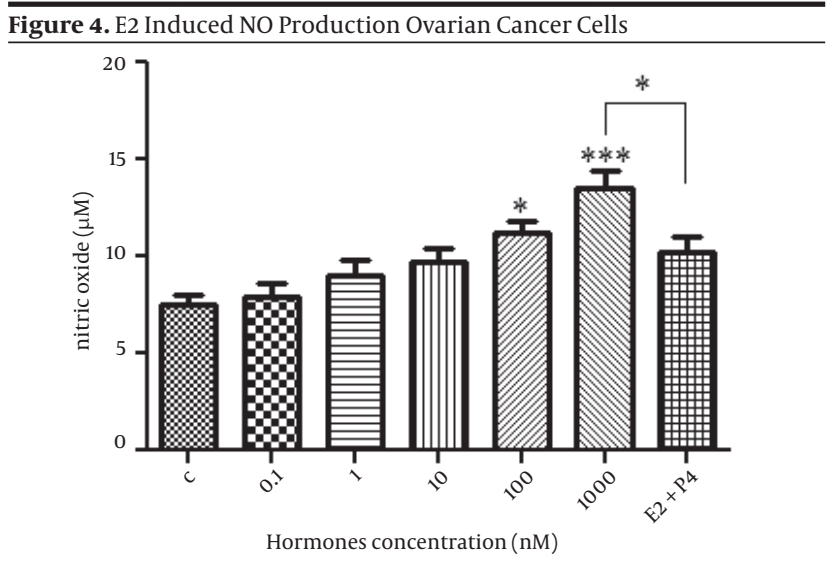

$\overline{\text { OVCAR-3 Cells Were Treated With Various Concentrations of E2 or Co-Treated }}$ With E2 $(1 \mu \mathrm{m})$ And Progesterone (P4) $(1 \mu \mathrm{m})$. The Data Shown is The Mean \pm SE From at Least Three Separate Experiments. ${ }^{*} \mathrm{P}<0.05 ;{ }^{* *} \mathrm{P}<0.01 ;{ }^{* * *} \mathrm{P}<0.001$.

\section{Discussion}

Reactive oxygen species (ROS) are constantly generated and eliminated in the biological system, and play important roles in a variety of normal biochemical functions and abnormal pathological processes (16). Mitochondria are considered the major source of cellular ROS (and are likely to play a significant role in ROS stress in cancer cells (17). Although, increased ROS stress in cancer cells may provide therapeutic strategies by further increasing ROS to kill cancer cells using pharmacological agents (18), ROS take part in survival signal activation and under persistent endogenous ROS stress cells become resistant (19). In the present study E2 was shown that be able to increased OVCAR-3 cell proliferation, which is evident by increased cell viability. It also induced intracellular ROS generation in a dose dependent manner. Interestingly, the optimal dose of E2 which was most effective on cell viability, caused the highest ROS generation in these cell. On the other hand, treatment of cells with NAC which is a potent antioxidant (20) and Ebselen which is a glutathione peroxidase mimetic (21), efficiently reduced E2induced ROS production. Intracellular ROS have been previously reported to activate signaling pathways which favor survival and proliferation of cells, both required for malignant transformation (3). ROS may serve as messengers in cellular signaling transduction pathways, and a moderate increase of certain ROS such as superoxide and hydrogen peroxide may promote cellular growth and proliferation and contribute to cancer development (22). The mechanisms responsible for stimulation of cell proliferation are likely to involve the direct ROS interaction with specific receptors and modulation of the redox states of signaling molecules such as protein kinases and transcription factors (23). ROS can affect MAPK signaling pathway which is involved in cell proliferation (16). Oxidative modifications of redox-sensitive transcription factors including NF-кB, and Hypoxia-inducible factor 1-alpha (HIF-1 $\alpha$ ) and intermediate signaling molecules such as Protein kinase C 
(PKC), Extracellular signal-regulated kinases (ERK), and c-Jun N-terminal kinases (JNK) have also been shown to be involved in ROS-mediated modulation of cell growth and cell survival. E2 exerts most of its effect through interaction with its intracellular receptor and ICI182780, a specific ER antagonist, inhibits most of its functions (24). In this study, co-treatment with E2 and ICI182780 caused a significant reduction in ROS levels, suggesting that ROS production by E2 is mediated through interaction of E2 with its receptor. However, studies have shown that E2 is able to induce ROS in cells even in ER negative cells, therefore it seems that both genomic and non-genomic pathways are involved in E2 mediated ROS production in cells $(3,25)$.

iNOS (inducible nitric oxide synthase) has been shown to be markedly expressed in different types of human tumors (26). A major proportion of human epithelial ovarian cancers express iNOS and NO production has been observed in ovarian tumors (27). NO is a pleiotropic regulator which is critical to numerous biological processes and is able to promote tumor growth, metastasis and angiogenesis. Similar to ROS, high levels of NO may be cytostatic or cytotoxic for tumor cells, whereas low levels can have the opposite effect and promote tumor growth (26). Estrogens have been shown to induce NO production and modulate nitric oxide activity in cells such as Neuroblastoma, endothelial and immune cells $(28,29)$, but its effect on ovarian cancer cells has not been previously described. In this study we found that E2 can increase NO levels in ovarian cancer cells this and progesterone can significantly reduce E2-induced NO generation. Whether this effect is mediated via iNOS activation in ovarian cancer cells requires fur-

ther studies.

\section{Acknowledgements}

This research has been conducted by grant from Iran University of Medical Sciences.

\section{Conflict of Interest}

The authors made no disclosures.

\section{References}

1. Cunat S, Hoffmann P, Pujol P. Estrogens and epithelial ovarian cancer. Gynecol Oncol. 2004;94(1):25-32.

2. Blomquist $\mathrm{CH}$, Leung BS, Zhang R, Zhu Y, Chang PM. Properties and regulation of 17 beta-hydroxysteroid oxidoreductase of OVCAR-3, CAOV-3, and A431 cells: effects of epidermal growth factor, estradiol, and progesterone. $J$ Cell Biochem. 1995;59(4):409-17.

3. Okoh V, Deoraj A, Roy D. Estrogen-induced reactive oxygen species-mediated signalings contribute to breast cancer. Biochim Biophys Acta. 2011;1815(1):115-33.

4. Zhu BT, Conney AH. Is 2-methoxyestradiol an endogenous estro- gen metabolite that inhibits mammary carcinogenesis? Cancer Res. 1998;58(11):2269-77.

5. Blomquist $\mathrm{CH}$, Bonenfant M, McGinley DM, Posalaky Z, Lakatua DJ, Tuli-Puri S, et al. Androgenic and estrogenic 17beta-hydroxysteroid dehydrogenase/17-ketosteroid reductase in human ovarian epithelial tumors: evidence for the type 1,2 and 5 isoforms. J Steroid Biochem Mol Biol. 2002;81(4-5):343-51.

6. Nourbakhsh M, Golestani A, Zahrai M, Modarressi MH, Malekpour Z, Karami-Tehrani F. Androgens stimulate telomerase expression, activity and phosphorylation in ovarian adenocarcinoma cells. Mol Cell Endocrinol. 2010;330(1-2):10-6.

7. Wehling M, Losel R. Non-genomic steroid hormone effects: membrane or intracellular receptors? J Steroid Biochem $\mathrm{Mol}$ Biol. 2006;102(1-5):180-3.

8. Chen JQ, Yager JD, Russo J. Regulation of mitochondrial respiratory chain structure and function by estrogens/estrogen receptors and potential physiological/pathophysiological implications. Biochim Biophys Acta. 2005;1746(1):1-17.

9. Cavalieri E, Frenkel K, Liehr JG, Rogan E, Roy D. Estrogens as endogenous genotoxic agents--DNA adducts and mutations. $J$ Natl Cancer Inst Monogr. 2000;(27):75-93.

10. Valko M, Leibfritz D, Moncol J, Cronin MT, Mazur M, Telser J. Free radicals and antioxidants in normal physiological functions and human disease. Int J Biochem Cell Biol. 2007;39(1):44-84.

11. Wu WS. The signaling mechanism of ROS in tumor progression. Cancer Metastasis Rev. 2006;25(4):695-705.

12. Park SA, Na HK, Kim EH, Cha YN, Surh YJ. 4-hydroxyestradiol induces anchorage-independent growth of human mammary epithelial cells via activation of IkappaB kinase: potential role of reactive oxygen species. Cancer Res. 2009;69(6):2416-24.

13. Pavlović D, Đorđević V, Kocić G. Cross-talk" between oxidative stress and redox cell signaling. Med Biol. 2002;2:131-7.

14. Tamanini C, Basini G, Grasselli F, Trelli M. Nitric oxide and the ovary. J Animal Sci. 2003;81(14 (suppl 2)):E1-7.

15. Yucel AA, Gulen S, Dincer S, Yucel AE, Yetkin GI. Comparison of two different applications of the Griess method for nitric oxide measurement. J Exp Integrat Med. 2012;2(2):167-71.

16. Pelicano H, Carney D, Huang P. ROS stress in cancer cells and therapeutic implications. Drug Resist Updat. 2004;7(2):97-110.

17. Richter C, Gogvadze V, Laffranchi R, Schlapbach R, Schweizer M Suter M, et al. Oxidants in mitochondria: from physiology to diseases. Biochimica et Biophysica Acta (BBA)-Molecular Basis of Disease. 1995;1271(1):67-74.

18. Baliga R, Ueda N, Walker PD, Shah SV. Oxidant mechanisms in toxic acute renal failure. Drug Metab Rev. 1999;31(4):971-97.

19. Acharya A, Das I, Chandhok D, Saha T. Redox regulation in cancer: a double-edged sword with therapeutic potential. Oxid Med Cell Longev. 2010;3(1):23-34.

20. Kerksick C, Willoughby D. The antioxidant role of glutathione and N-acetyl-cysteine supplements and exercise-induced oxidative stress. J Int Soc Sports Nutr. 2005;2:38-44.

21. Schewe T. Molecular actions of ebselen--an antiinflammatory antioxidant. Gen Pharmacol. 1995;26(6):1153-69.

22. Schimmel M, Bauer G. Proapoptotic and redox state-related signaling of reactive oxygen species generated by transformed fibroblasts. Oncogene. 2002;21(38):5886-96.

23. Liu H, Nishitoh H, Ichijo H, Kyriakis JM. Activation of apoptosis signal-regulating kinase 1 (ASK1) by tumor necrosis factor receptor-associated factor 2 requires prior dissociation of the ASK1 inhibitor thioredoxin. Mol Cell Biol. 2000;20(6):2198-208.

24. Bai W, Oliveros-Saunders B, Wang Q, Acevedo-Duncan ME, Nicosia SV. Estrogen stimulation of ovarian surface epithelial cell proliferation. In Vitro Cell Dev Biol Anim. 2000;36(10):657-66.

25. Okoh VO, Felty Q, Parkash J, Poppiti R, Roy D. Reactive oxygen species via redox signaling to PI3K/AKT pathway contribute to the malignant growth of 4-hydroxy estradiol-transformed mammary epithelial cells. PLoS One. 2013;8(2):e54206.

26. Weiming XU, Liu LZ, Loizidou M, Ahmed M, Charles IG. The role of nitric oxide in cancer. Cell Res. 2002;12(5):311-20.

27. Anttila MA, Voutilainen K, Merivalo S, Saarikoski S, Kosma VM. Prognostic significance of iNOS in epithelial ovarian cancer. 


\section{Maleki Jet al.}

Gynecol Oncol. 2007;105(1):97-103.

28. Cho MM, Ziats NP, Pal D, Utian WH, Gorodeski GI. Estrogen modulates paracellular permeability of human endothelial cells by eNOS- and iNOS-related mechanisms. Am J Physiol. 1999;276(2 Pt 1):C337-49.
29. Karpuzoglu E, Ahmed SA. Estrogen regulation of nitric oxide and inducible nitric oxide synthase (iNOS) in immune cells: implications for immunity, autoimmune diseases, and apoptosis. Nitric Oxide. 2006;15(3):177-86. 